\title{
Hallux valgus with or without metatarsalgiae
}

\section{GECO, January 1990}

Gérard Copin ${ }^{1}$ and Christian Debaëne ${ }^{2}$

${ }^{1}$ CTO, avenue Achille-Baumann, BP 96, F-67400 Illkirch-Graffenstaden, France

${ }^{2}$ Hôpital de Wissembourg, F-67160 Wissembourg, France

More than thousand files on operated hallux valgus have been revised by the permanent members of the GECO fot the 14th Enlarged Meeting held at Les Arcs in January 1990.

The computerized study has been realized in Strasbourg for 846 files and in Dijon for the 177 remaining others.

The aim of this work was to be able to compare the results of the various operative techniques and to draw out an operative indication, the importance of the initial deformation of the hallux valgus being taken into account.

After a quote on the physio-pathogeny of the hallux valgus by Max Perrin, the clinical symptomatology of the studied series was presented by Christian Debaene, when the radiographical aspect was naturally the competence of Jean-Claude Dosch.

The different operative techniques have been gathered by Gérard Copin, in five chapters, reminding their historic conception and the operative methods :

1. The oldest technique is the metatarsal exostosectomy of Schede.

2. The operations on soft parts consist in :

- the isolated recentring of the sesamoïdal belt described in 1904 by Keller, taken up again in 1935 by Morton, and spread in France by Lelièvre, in his book in 1961,

- the external freeing metatarsophalangial with tenotomy of the abductor, described in 1875 by Petersen and reintroducted in France by
Roy-Camille in 1962,

- the tenodesis transposition of the abductor describe in 1928 by Mac Bride and spread in France by Meary.

3. The methods of osseus reaxation include :

- the osteotomy of the proximal P1 phalanx described by Giannestras and spread in France by Gauthier,

- the osteotomy of the M1 metatarsal base most fashionable in the departments of Groulier in Marseille and Delagoutte in Nancy enabling the association of both osteotomies at the level of M1 and P1 during the same operation.

- the under-capital osteotomy of M1, described by Hohmann in 1921,

- the bi-polar osteotomy of M1, described by Schnepp and Carret in Lyon.

4. The metatarso-phalangal arthroplasties of the big toe consist in :

- the classical operation of KellerBrandes with resection of the base of $\mathrm{P} 1$, associated with the recentring of the sesamoidal belt according to Lelièvre, without forgetting the fixation of the sesamoïds to the flexor tendon and the stump of P1, to avoid their backward movement, according to Antonio Viladot,

- the osteo-cartilageneous reimplantation of the base of P1 described by Regnaud in Nantes,

- the arthroplasty by sylastic implant of Swanson, metatarso-phalangial, proposed in 1973 by
Michon, Delagoutte and Jandeaux parallel to the use of a sylastic implant of the base of P1, cork-type.

5. The metatarso-phalangial arthrodesis which perpetuates the reduction of big deformation, while letting a satisfactory fonction persist by the inter-phalangial mobility.

In this study, the preference of some And others has been taken into account for a particular technique, in entrusting them the analysis of cases operated according to this technique.

It has to be mentionned that the population of hallux valgus is almost similar in each series of cases operated according to an operative technique, taking into account the age, the importance of the deformation and the associated.

20 cases of exostosectomy and recentring of the sesamoïdal belt were analysed by Christian Debaene, whereas the 142 recentring of the sesamoïdal belt with dorsal freeing of the toes, were presented by Max Perrin in who had operated them.

PatriceDiebold saw again the 113 cases of operation of Petersen performed in Nancy.

Jean Berger, with a special study of the hallux valgus in the child, analysed the 36 cases of Mac Bride operations on the adult.

Jean-Claude Schwartz dealt with 66 cases of M1, metatarsal basal osteotomy and with P1 phalangal osteotomies performed in Colmar. 
The 284 cases of under-capital osteotomy of M1, according to Hohmann, have been analysed by Gérard Copin.

The 102 cases of arthoplastic resection according to Keller-Brandes have been taken up again by Jean-Claude Steib.

The 104 cases of metatarso-phalangal implants of Swanson have been presented by Michel Jandeaux, who had inserted them.

Philippe Segal took up again the 50 cases of metatarso-phalangal arthrodesis of the big toe.

In most cases, the metatarsalgiae are part of the clinical pattern of hallux valgus from fonctional insufficiency of the first range foothold. They are bettered by treating the hallux valgus. However, in certain cases, the metatarsalgiae do persist, and secondarily motivated a reoperation by osteotomy with resection at the level of the base of medial metatarsal M2, M3, M4, enabling the lifting up and setting back of metatarsal heads. A short series of the association of this osteotomy to the operation of Hohmann is presented by Gérard Copin.

Finally, Jacques Xenard after having studied the post-operative follow-ups of all these operations, quoted the methods of functional physiotherapy and fitting out of these treated feet.

The global results showed that the treatment of the hallux valgus was always beneficial but the results depended on the importance of the initial hallux valgus and the operative techniques.

Considering these techniques, the following operative indications may be suggested :

- the hallux valgus, starting but painful, whose metatarso-phalangal deformation is inferior to $30^{\circ}$, is part of Mac Bride or Petersen operation, being careful about the risks of hyper-correction of these operations.

- the usual $30^{\circ}$ to $45^{\circ}$ hallux valgus will benefit at the best from metatarsal osteotomy techniques, either from the base associated to a recentring of the sesamoïdal belt with an exostosectomy, or of the extra-articular metatarsal neck according to Hohmann enabling to get the best foothold strength of the big toe pulp,

- the hallux valgus, when very important, superior to $50^{\circ}$, will be stabilized at best by a metatarso-phalangal arthrodesis, although the Swanson arthroplasty is competitive.

But this one is spoilt by biology critics of intolerance to sylastic, which has nevertheless not been noted in the present series,

- we cannot advise the KellerBrandes operation anymore, even in the old aged, who will benefit at best from the metatarso-phalangal arthrodesis, neither the return under isolated tension of the sesamoïdal belt, according to Lelièvre, although one of us, Max Perrin, is pleased with it, under the condition of associating it with the dorsal freeing of the toes correcting the metatarsal enclosing.

Thus, in front of the maze of the multiplicity of the operative techniques, we did give ourselves an Ariadne's dew in order to treat at best each particular case of hallux valgus. 